\title{
Polymorphic Ventricular Tachycardia
}

National Cancer Institute

\section{Source}

National Cancer Institute. Polymorphic Ventricular Tachycardia. NCI Thesaurus. Code C111648.

A ventricular tachycardia that is irregular in rate and rhythm. 